\title{
Marcas polifónicas en las Columnas sobre la lengua en la prensa española ${ }^{1}$
}

\section{Polyphonic markers within language columns in the Spanish press}

\author{
Ana Pano Alamán \\ Università di Bologna, Bologna, Italia \\ ana.pano@unibo.it
}

\section{A ACCESO ABIERTO / OPEN ACCESS}

Cita: Pano Alamán, Ana (2020). Marcas polifónicas en las Columnas sobre la lengua en la prensa española. Textos en Proceso, 6(2), pp. 128-145. https://doi.org/10.17710/tep.2020.6. 2.9panoalaman

Editoras: Susana Guerrero Salazar y Carmen Marimón Llorca

Recibido: 10/10/2020

Aceptado: 02/11/2020

Conflicto de intereses: La autora ha declarado que no posee conflicto de intereses.

Copyright: (c) Ana Pano Alamán. Esta obra está bajo licencia Creative

Commons Reconocimiento 4.0

\section{Resumen}

En este artículo se presentan los resultados de un primer análisis cualitativo sobre las principales manifestaciones de la polifonía en un corpus de Columnas sobre la lengua (CSL) publicadas en la prensa española entre 1959 y 2019. El análisis, basado en los principales planteamientos de la teoría polifónica, tiene como objetivos, en primer lugar, identificar las marcas polifónicas que aparecen en artículos de opinión en los que sus autores describen y evalúan determinados usos lingüísticos del español; y en segundo lugar, determinar las funciones discursivas que desempeñan los enunciados polifónicos en estos textos. Los resultados de este análisis muestran que los autores de las CSL analizadas combinan diversos dispositivos de reproducción del discurso, como la cita directa e indirecta, el perspectivismo dialógico, los enunciados interrogativos y la ironía verbal, que los autores emplean con fines argumentativos y persuasivos para evaluar los usos lingüísticos de determinados hablantes y establecer una relación de complicidad con el lector.

Palabras clave: columna sobre la lengua, polifonía, argumentación, persuasión, ironía.

\section{Abstract \\ This paper presents the results of a first qualitative analysis of the main indicators of polyphony within a corpus of Columns on language (CSL) published in the Spanish press (1959-2019). Based on the polyphonic theory assumptions, this study aims at identifying the main polyphonic marks employed within these opinion

\footnotetext{
${ }^{1}$ Este trabajo se enmarca en el Proyecto I+D+i PID2019-107265GB-I00 El columnismo lingüístico en la prensa española desde sus orígenes. Análisis multidimensional, caracterización y aplicaciones (METAPRES-COLING).
} 
articles, where certain linguistic uses of Spanish are described and evaluated, as well as detecting the discursive functions that polyphonic sentences perform in the same texts. The results show that the authors of these columns combine different linguistic means and discursive strategies, such as the direct and indirect reproduction of others' discourses, as well as dialogic perspectivism strategies, interrogative statements, and verbal irony. They put these strategies at the service of argumentation for or against certain linguistic uses, and of persuasion, in order to establish a sort of complicity with the reader.

Keywords: columns on language, polyphony, argumentation, persuasion, irony.

\section{Introducción}

Las ideologías lingüísticas se definen como sistemas de ideas o marcos cognitivos "que articulan nociones del lenguaje, las lenguas, el habla y/o la comunicación con formaciones culturales políticas y/o sociales específicas" (Del Valle, 2007, p. 15). Estas suelen vehicularse a través de opiniones o a través de conceptualizaciones de uso habituales en los estudios lingüísticos, como es el caso del purismo, el prestigio de una lengua o una variedad o la idea de norma ejemplar. En este sentido, es frecuente que, a través de ellas, se cree un imaginario del idioma o imaginario lingüístico (Houdebine, 2002), que suele conectarse con los intereses políticos y económicos de un determinado grupo. No en vano, las ideologías lingüísticas se entienden como representaciones de la intersección entre el lenguaje y la dimensión social de la actividad humana y remiten a la carga de intereses morales y políticos inscritos en esas representaciones (Schieffelin, Woolard y Kroskrity, 2012 [1998], p. 5). Por otra parte, las representaciones sociocognitivas sobre la lengua, socialmente compartidas, conducen a prácticas sociales discursivas y no discursivas de los grupos sociales (Van Dijk, 2011).

En este contexto, los medios de comunicación desempeñan un papel central, pues, como han señalado Marimón Llorca $(2015,2018)$ y Marimón Llorca y Santamaría Pérez (2019), estos participan activamente en la creación de representaciones sociales sobre la lengua y en la orientación y justificación de las mismas. Los medios se ocupan de cuestiones sobre la lengua, como son la norma o el cambio lingüístico, a través de noticias, artículos de opinión o reportajes, en los que se dedica atención a temas que suelen generar polémica, como son el sexismo en la lengua, la planificación lingüística o el abuso de anglicismos, entre muchos otros (Carriscondo Esquivel y Guerrero Salazar, 2015).

Dentro del género de los artículos de opinión dedicados a estos temas, destacan las Columnas sobre la lengua (CSL) que se publican regularmente en la prensa escrita y digital. De acuerdo con Marimón Llorca (2020, p. 14), estos son textos que tratan sobre la lengua y que "constituyen la expresión libre de la ideología lingüística de un individuo que, con periodicidad, vierte sus opiniones sobre el uso que sus contemporáneos hacen de ella". Para la autora, además de ser textos normativos, argumentativos y persuasivos, es posible situarlos dentro de una tradición discursiva metalingüística ${ }^{2}$, puesto que presentan patrones formales y

\footnotetext{
${ }^{2}$ Están constituidos por proposiciones metalingüísticas, "juicios para los cuales la responsabilidad es asumida por un sujeto cuyo discurso se refiere a un objeto (el lenguaje) por medio del lenguaje en sí" (González Ruiz y Loureda Lamas, 2005, pp. 355-356).
} 
composicionales propios del columnismo, se apoyan en recursos pragmáticoenunciativos recurrentes y vehiculan ciertas ideologías lingüísticas que los conectan con un determinado contexto sociocultural (Marimón Llorca, 2020, pp. 118-119). El autor de la columna evalúa usos del idioma que considera en muchas ocasiones inadecuados o inaceptables y justifica su postura, generalmente, en relación con la norma lingüística dominante, como puede ser la norma académica (Marimón Llorca, 2018), o con su propia idea de norma ejemplar (Pano Alamán, 2019). En este sentido, las CSL representan también un tipo de discurso epilingüístico de carácter pedagógico, en el que con un enfoque prescriptivo o descriptivo, se señalan las consecuencias del decir y no decir algo en ciertas situaciones (Remysen, 2005, pp. 272-273). Asimismo, el autor de este tipo de textos suele elaborar ante el lector un ethos discursivo que busca persuadir a los lectores, mediante, por ejemplo, actos de habla que permiten desplazar la responsabilidad de lo que se dice desde el autor real hacia el sujeto hablante o enunciador, para conseguir que el lector se adhiera al punto de vista que se defiende (Marimón Llorca, 2016, p. 85).

En relación con este último aspecto, en este trabajo se presentan los resultados de un análisis discursivo cualitativo sobre la presencia y funciones de la polifonía en un corpus de CSL publicadas en la prensa española por lingüistas, académicos, filólogos, periodistas y escritores en un lapso de tiempo de cuarenta años. El principal objetivo de este estudio es comprobar en qué medida la polifonía es una estrategia pragmático-enunciativa caracterizadora de las CSL publicadas durante décadas en la prensa española.

\section{Marco teórico}

Como han apuntado diversos estudios sobre el discurso periodístico en español (Méndez García de Paredes, 2000, 2001; Casado Velarde, 2010; Escribano Hernández, 2009, entre otros), la presencia de diferentes fuentes informativas y la pluralidad de voces, en forma de declaraciones, relatos, reacciones verbales, son aspectos caracterizadores de este tipo de discurso, que es esencialmente polifónico.

El concepto de polifonía señala que en la enunciación concurren diferentes voces que se superponen, aunque, aparentemente, el sujeto que habla sea el mismo. En conexión con esta idea de multiplicidad del sujeto enunciativo es posible afirmar que todo discurso tiene ecos de otros discursos. En este sentido, conceptos como dialogismo e intertextualidad permiten abordar ese entramado discursivo mediante el análisis de dispositivos como el préstamo directo, la libre interpretación, la parodia o el comentario. En concreto, el concepto de dialogismo alude a las relaciones que todo enunciado mantiene con otros producidos anteriormente y con potenciales enunciados futuros (Bajtin, 1981). Desde este enfoque, se asume que toda palabra empleada en el discurso "supone una articulación con palabras previas o posteriores, reales o imaginarias, e inscribe en sí misma una posición subjetiva definida por su relación con la alteridad" (García Negroni, 2017, p. 525).

Inspirándose en las aportaciones de Bajtin, Ducrot (1984) elabora una teoría polifónica de la enunciación según la cual el concepto de sujeto unitario se divide en sujeto empírico (sujet parlant) productor real del enunciado; locutor (locuteur), una ficción discursiva a la que se imputa la responsabilidad del enunciado; y enunciador (énonciateur), persona cuyo punto de vista presenta los acontecimientos expresados en el enunciado. Respecto al locutor, Ducrot distingue entre locutor como tal (L), responsable de la enunciación, y locutor como ser del mundo (l), a quien remiten las marcas de primera persona y de quien se habla en el enunciado 
que contiene dichas marcas. En cuanto a la segunda figura, el enunciador, se trata de uno o más puntos de vista que se manifiestan en el enunciado, con los que L no se identifica necesariamente (Ducrot, 1984, p. 208; García Negroni y Tordesillas Colado, 2001). Según la concepción polifónica del discurso, el sentido nace de la superposición de los diversos puntos de vista que se expresan en la enunciación y de la actitud que el locutor L adopta frente a ellos. Este es el responsable de la enunciación, por ello, es la figura a quien compete la responsabilidad de seleccionar a los enunciadores, identificándose con ellos o bien oponiéndose.

\subsection{Recursos polifónicos en el discurso periodístico}

En el discurso mediático, quien escribe cuenta con una gran variedad de procedimientos gramaticales y discursivos para hacer intervenir a distintos enunciadores sin perder el control del sentido que pretende dar al propio discurso (Casado Velarde y Lucas, 2013, p. 333). Como señalan diversos estudios (Reyes, 1993; 1994; Maldonado, 1999), los modos habituales de integrar un discurso en otro son el estilo directo, el indirecto y algunas formas mixtas o variantes de las dos primeras. La estructura canónica del estilo directo está constituida por una expresión introductora, que contiene un verbo de lengua, una cita directa marcada tipográficamente por guiones o comillas, y el contenido citado. El segundo de los miembros, aquel que contiene el discurso referido, se caracteriza por conservar las marcas deícticas del parlamento del hablante citado, en este sentido, las secuencias no llegan a trabarse como en el estilo indirecto (Maldonado, 1999: 3551).

En la Nueva Gramática de la Lengua española (2009, p. 3274), se explica que tanto el estilo directo como el indirecto requieren generalmente la presencia de un verbo de lengua (verba dicendi) introductor, como decir, explicar, opinar, repetir o responder, que pueden aparecer antes de la cita, intercalado en ella o bien pospuesto, en posición final. Estos procedimientos prevén también la posibilidad de citar un enunciado sin comillas o parcialmente entrecomillado, dependiendo de la intención del autor (Estévez Rionegro, 2012, p. 338).

Abundan en el discurso periodístico otros procedimientos de cita que combinan ambas posibilidades. El estilo directo libre o discurso directo sin marco explícito reproduce los enunciados de forma literal pero carece de verbo introductor. La cita puede conservar las marcas tipográficas (comillas o guiones) o bien eliminarlas. Se trata de una variante caracterizada por "la ausencia de verbos de lengua o de pensamiento, así como de otras marcas lingüísticas" (Maldonado, 1999, p. 3275). El estilo indirecto libre alterna, en cambio, los centros deícticos que corresponden al locutor y a los distintos enunciadores, de manera que el discurso del primero se contamina de ecos ajenos sin llegar a convertirse en un discurso referido.

Es necesario señalar que el discurso referido no es solo un procedimiento gramatical para reproducir un discurso, sino que implica, en particular en los géneros periodísticos de opinión como la columna lingüística, una actitud activa de un discurso respecto a otro. En estos textos siempre hay

por parte del discurso que acoge una especie de evaluación de lo dicho por otro de réplica [...] que empieza por la propia elección de lo referido (qué partes del discurso del otro interesa destacar como tema del nuevo discurso), sigue con la explicitación de la intención comunicativa de esas palabras y termina con la elección del tipo de 
discurso referido (en estilo directo o en estilo indirecto o en otras variantes) (Méndez García de Paredes, 2000, p. 149).

Desde esta perspectiva, la construcción polifónica está subordinada a una finalidad argumentativa (Casado Velarde, 2010, p. 71), bien para apoyar lo que se dice en el enunciado reproducido, bien para ponerlo en tela de juicio, por ejemplo, por medio de la desautorización de "la voz heteroglósica". Una de las estrategias más empleadas en el discurso periodístico para evaluar al enunciador y a su discurso es precisamente la elección de los "verbos introductores de cita" (De Lucas, 2017), puesto que vehiculan un significado que condiciona la manera en el que receptor interpretará el discurso citado, imponiendo así, una cierta lectura al destinatario (Maldonado, 1999: 3559).

Junto a los verbos introductores, Casado Velarde (2010, p. 75) considera otros recursos de distanciamiento con efecto desautorizador respecto al enunciado o segmento del enunciado que se inserta en el propio discurso. Se trata de las expresiones llamado/-a, que llaman, el indicador sic, la forma dixit, la inclusión de algún elemento entre comillas o en cursiva o la introducción en el discurso de algún elemento lingüístico colocado entre guiones en el discurso reproducido. En este sentido, es posible considerar también el valor polifónico que pueden tener las estructuras parentéticas (Fuentes Rodríguez, 1998).

Otro recurso asociado a la polifonía, analizado generalmente en textos literarios pero presente también en los géneros periodísticos de opinión, es el llamado perspectivismo dialógico, que prevé la reproducción en el texto de un diálogo, real o fingido, cuyo objeto es ampliar la complejidad psicológica de los enunciadores, y acercar el texto al lector (Villa García y Arroyas Langa, 2019, p. 106). Por medio de la oralidad fingida el locutor señala la inmediatez de los acontecimientos y aporta verosimilitud a la situación de enunciación que se reelabora discursivamente. Por otra parte,

el perspectivismo dialógico contribuye también a abrir la narración a una pluralidad de enfoques mediante el intercambio verbal de los personajes como una forma de limitación de la presencia del narrador, que pasa a un segundo plano para crear el efecto de que no está por encima de sus lectores y la ilusión de no imponer sus puntos de vista como tal (p. 107).

En el discurso periodístico de opinión juega un papel fundamental también la cita de autoridad, estrategia argumentativa que se apoya en la credibilidad que poseen ciertas personas, grupos o instituciones, cuyos enunciados se consideran socialmente como verdaderos y que se citan como pruebas en favor de una tesis (Perelman y Olbrechts-Tyteca, 1994 [1958], p. 470). Por otra parte, los enunciados interrogativos presentan valores discursivos polifónicos cuando la interrogación está orientada a que el interlocutor confirme la suposición de quien la realiza. La polifonía deriva de la respuesta afirmativa que el locutor incluye de forma implícita

\footnotetext{
${ }^{3}$ Respecto al tipo de verbos que se emplean, existen discrepancias entre los autores que, como Reyes (1993) y Méndez García de Paredes (2001), incluyen los lexemas verbales de carácter epistémico dentro del grupo de los de lengua porque "transmiten, verbalizándolos, los contenidos del pensamiento o la percepción” (Reyes, 1993, p. 19), y otros, como Maldonado (1999), que los excluyen.

${ }^{4}$ Para una perspectiva más amplia sobre el papel de estos verbos en la conceptualización de las situaciones que describen los enunciados en el discurso periodístico, véase Martínez Linares (2019), que analiza este aspecto a partir del estudio de las columnas lingüísticas de Álex Grijelmo.
} 
en la interrogación y que coincide con su propia opinión (Escribano Hernández, 2017, p. 119).

Dentro del estudio sobre usos polifónicos, se ha incluido también la negación polémica, mediante la cual se manifiestan puntos de vista antagónicos generados por la oposición entre la negación explícita y el contenido presupuesto, esto es, la correspondiente oración afirmativa implícita (Ducrot, 1986 [1984], p. 222). La negación tendría de hecho un carácter de cita encubierta, puesto que el enunciado que se niega puede ser algo dicho anteriormente en una conversación, una suposición sociocultural, una expectativa conocida de nuestro interlocutor (NGLE, 2009, p. 3639).

Por último, desde un enfoque polifónico del discurso, cabe considerar la ironía 5 . El concepto de enunciadores permite entender cómo los distintos puntos de vista que el hablante yuxtapone en un enunciado pueden oponerse implícitamente con fines irónicos (Bruzos Moro, 2009). El enunciado irónico puede apoyarse en el desdoblamiento implícito entre el yo hablante que corresponde al locutor y otros enunciadores, entre los que se establece un juego de perspectivas. La ironía se insinúa cuando el locutor expresa su propio pensamiento, comunicando en realidad un pensamiento ajeno del que de hecho se disocia en mayor o menor grado.

En este sentido, de acuerdo con el enfoque dialógico de la argumentación y la polifonía (García Negroni, 2017), es necesario considerar el concepto de puntos de vista evidenciales, que pueden ser directos cuando "contienen instrucciones dialógico-causales que obligan a recuperar marcos de discurso previos o previstos", o alusivos, cuando contribuyen a "rememorar dialógicamente lo 'ya dicho' en el interdiscurso [...] y permiten establecer un lazo de complicidad con el destinatario que reconoce esas huellas como parte de la 'memoria discursiva"'. Si es directo, la posición subjetiva del hablante se transmite a través de una enunciación fuertemente asertiva; si es indirecto, se manifiesta mediante formas asertivas atenuadas, en función del marco de discurso evocado (García Negroni, 2017, pp. 525-527).

\section{Marco metodológico y descripción de los datos}

Los objetivos específicos de este estudio son identificar las principales marcas polifónicas empleadas en un corpus de CSL y determinar sus funciones discursivas en este tipo de textos. Para ello, se ha realizado un análisis pragmalingüístico cualitativo basado en los planteamientos de la teoría polifónica y en los estudios mencionados sobre los procedimientos gramaticales y pragmático-discursivos (Tabla 1) adoptados para insertar distintas voces en el texto periodístico de opinión. El estudio se ha realizado sobre un corpus constituido por $150 \mathrm{CSL}$, extraídas de la base de datos del proyecto METAPRES (Tabla 1). Los textos cubren el periodo 1959-2019 y abordan distintos aspectos sobre la lengua española relacionados en gran parte con la norma académica, los usos generales y especializados del léxico, los discursos periodístico, político y jurídico-administrativo, los extranjerismos y las traducciones. Las columnas están firmadas por lingüistas, filólogos, académicos, periodistas y escritores españoles.

\footnotetext{
${ }^{5}$ Afirma Ducrot que "Hablar de manera irónica equivale, para un locutor L, a presentar la enunciación como si expresara la posición de un enunciador E, posición que por otra parte se sabe que el locutor L no toma bajo su responsabilidad y que, más aún, la considera absurda" (1986 [1984], p. 215).
} 
Tabla 1. Corpus de análisis

\begin{tabular}{|l|l|l|l|}
\hline Autor & Título columna & N. ${ }^{\mathbf{0}}$ CSL & Selección \\
\hline Julio Casares & $\begin{array}{l}\text { La Academia Española trabaja (1959- } \\
1964)-A B C\end{array}$ & 59 & 15 \\
\hline Ramón Carnicer & $\begin{array}{l}\text { Sobre el lenguaje (1966-1983) - La } \\
\text { Vanguardia }\end{array}$ & 450 & 15 \\
\hline Fernando Lázaro Carreter & $\begin{array}{l}\text { Dardo en la palabra / Nuevo dardo en la } \\
\text { palabra (1975-2003) - Informaciones, } \\
\text { ABC, El País }\end{array}$ & 291 & 15 \\
\hline Luis Calvo-Brocense & Diálogo de la lengua (1980-1984) - ABC & 160 & 15 \\
\hline Marqués de Tamarón & El Habla Nacional (1985-1988) - ABC & 74 & 15 \\
\hline Emilio Lorenzo & (1982-2002) - ABC & 54 & 15 \\
\hline Luis Cortés & $\begin{array}{l}\text { El español que hablamos (2009-2011) - } \\
\text { La Voz de Almería }\end{array}$ & 108 & 15 \\
\hline Amando de Miguel & $\begin{array}{l}\text { Errores y Erratas (2002-2005) - Libertad } \\
\text { digital }\end{array}$ & 519 & 15 \\
\hline Luis Magrinyá & $\begin{array}{l}\text { Lengua y Literatura (2009-2014) - El } \\
\text { País }\end{array}$ & 22 & 15 \\
\hline Álex Grijelmo & $\begin{array}{l}\text { La Punta de la Lengua (2013-2018) - El } \\
\text { País }\end{array}$ & 80 & 15 \\
\hline Total & & $\mathbf{1 8 1 7}$ & $\mathbf{1 5 0}$ \\
\hline
\end{tabular}

\section{Análisis de los datos y discusión}

De entrada, el análisis de los datos revela que los textos analizados emplean de forma prevalente la cita directa. A través de el estilo directo prototípico, los columnistas reproducen, supuestamente de forma literal, enunciados, expresiones y palabras, que han leído o escuchado en los medios, o que les han sido referidos por los lectores mediante cartas. La inserción en los textos de estas citas literales permite generalmente introducir el elemento lingüístico que se evalúa negativamente en la columna. Se trata de sustantivos, adjetivos o verbos que es necesario contextualizar asociándolos a un determinado enunciado, para poder después indicar por qué deberían evitarse, de acuerdo con su idea de norma ejemplar. Como se puede observar en (1), Fernando Lázaro Carreter cita, en primer lugar, las palabras de un necrólogo en los que se encuentra el elemento lingüístico que se apresta a comentar: "inhumados"; en segundo lugar, cita un enunciado interrogativo que contiene cierta ironía, empleando las palabras del lector que le ha remitido la nota -"esta joyuela"donde se encuentra el texto citado inicial:

1) Y explica el necrólogo: "Sus restos fueron inhumados el dia $28 \mathrm{y}$, por su voluntad expresa, serán esparcidos en el mar”. Me envía esta joyuela un anónimo lector — se la agradezco-, que comenta lacónico: “¿Pensará el autor que los restos fueron ahumados?". Tiene razón: inhumar es, simplemente, enterrar, porque humus era 'tierra' en latín, y para esparcir un cadáver inhumado habría que exhumarlo previamente, trocearlo y hacerlo picadillo. Sólo asi se le podría dispersar y aventar y desparramar sobre las olas (FLC, "Perdonar", El dardo en la palabra, 1995, p. 702).

En ambos casos, el columnista, que critica burlonamente al primer hablante por emplear "inhumados" en lugar de "incinerados" y que comparte, en cambio, el punto de vista con el lector, utiliza verbos de lengua (explicar, comentar) para introducir la cita que aparece entrecomillada, de este modo, aporta verosimilitud a lo dicho por el primer enunciador y se identifica con el segundo, haciendo suya también la pregunta, que contiene ya una actitud crítica y una intención irónica al sugerir una posible confusión del necrólogo entre las formas "incinerados" y 
“ahumados". Véase cómo Lázaro Carreter enriquece el marco de la segunda cita asociando al verbo de lengua "comentar" el adjetivo "lacónico", esto es, breve y conciso. En el segundo ejemplo, extraído de una columna de Luis Calvo, firmada con el seudónimo El Brocense, el autor cita entre comillas lo que "dicen que dijo" un político extranjero; pero dentro de esa misma cita se emplean las comillas para citar precisamente el verbo que el columnista pone bajo sospecha por su empleo inadecuado y quizá excesivo ("rehuimos la jeta de ese verbo"):

2) Cada día vemos, en periódicos, en libros, en discursos, vemos y rehuimos la jeta de ese verbo. "Felipe González 'detenta' el poder ejecutivo en nuestra Monarquía parlamentaria"; así dicen que dijo un visitante político extranjero, hace poco (El Brocense, "Del obstinado verbo 'comportar"', $A B C, 20 / 08 / 1983$, p. 46).

Aquí el verbo de lengua (decir) y el supuesto autor de la cita ("visitante político extranjero") se posponen al enunciado reproducido, lo cual no impide que el lector identifique la fuente de ese discurso. Las comillas que encierran el verbo dentro del enunciado citado llevan a pensar que ese es el único elemento literalmente dicho por ese enunciador, pero también permiten al columnista focalizar su atención sobre el verbo. En la medida en que utiliza "así dicen", el Brocense parece indicar que quizá el enunciado que se reproduce no es exactamente literal, sino fruto de la reelaboración de alguien que el locutor no conoce o no quiere nombrar.

En el caso que sigue, Emilio Lorenzo cita las palabras contenidas en una definición del diccionario académico, que aparecen entrecomilladas y con el verbo decir pospuesto, dentro de un inciso en el que busca aclarar el significado de la palabra "seriales", palabra que se "infiltra en los usos":

3) Están ahí elementos poco conspicuos de una quinta columna, desdibujados como debe ser, bien infiltrados en los usos y costumbres de cada día, confundidos con lo propio y familiar. Una vez son los seriales radiofónicos (no lo "perteneciente o relativo a una serie!", como dice el Diccionario de la Real Academia, sino la serie en sí), otra vez el silbido callejero sustituto del piropo, [...] o las tarjetas que exhiben en la solapa los dinámicos "ejecutivos", que en "convenciones" y congresos nos dicen sin hablar su nombre y procedencia o proclaman, en sitios selectos, que el portador es "de la casa" (EL, sin nombre, $A B C, 07 / 01 / 1984$, p. 003).

Con intención similar, cita entre comillas otras palabras a su parecer censurables, que pone en boca de determinados "ejecutivos". En este caso, el locutor se distancia de lo dicho por estos enunciadores, una estrategia que se ve reforzada gracias al marco de la cita en el que afirma "nos dicen sin hablar su nombre" y "proclaman, en sitios selectos, que el portador es 'de la casa". De este modo, no solo critica esas palabras, sino que señala la mala educación de este tipo de hablantes.

La cita directa es un mecanismo persuasivo eficaz porque produce "una intensa sensación de contacto directo entre los actores del proceso comunicativo y, por tanto, el texto le resulta más fiable al lector" (Escribano Hernández, 2017, p. 114). Se reproducen las palabras de otra persona manteniéndolas aparentemente idénticas a como fueron pronunciadas o escritas. Véase, por ejemplo, en (4), cómo las palabras entrecomilladas de uno de los lectores que escriben a de Miguel, se afirman "rotundamente con una doble negativa": 
4) Xosé Nel Caldevilla Vega (Xixón, Asturias) afirma rotundamente con una difícil doble negativa: "no va a encontrar lingüista que diga que el asturiano no es un idioma". Para don Xosé el asturiano es su lengua propia y "como puede observar, no me manejo nada mal con el castellano". El hombre es nada menos que "licenciado en Filología Clásica, especialidad en Latín, por lo que me da que en esto de lenguas sé algo más que usted y su amigo Navia Osorio". No me cabe duda de que don Xosé sabe más que yo de lenguas, pero aquí se trata de opinar con la experiencia que cada uno haya acumulado (ADM, "Lenguas hispánicas", Libertad Digital, 11/05/2009).

El ejemplo muestra que en estos textos suelen combinarse distintos procedimientos, como el empleo de comillas sin verbo introductor. Estos mecanismos, ampliamente utilizados en las CSL por todos los columnistas, sirven en algunos casos de pretexto para comentar algún aspecto peculiar del discurso que se cita. Véase el siguiente ejemplo de una columna de Luis Cortés en la que se cita literalmente un largo discurso sobre el estado de la Nación del expresidente Mariano Rajoy. Este fragmento citado literalmente permite al autor comentar el uso y abuso de las figuras de la oratoria en el lenguaje político español:

5) Obviamente, mucho más sofisticados son los mecanismos empleados en lenguajes formales como el jurídico, el publicitario, el político, etc. [...]. Por ejemplo, veamos el final del discurso inicial emitido por Rajoy en el último:

Debate en torno el estado de la Nación" (2011): No diré que baste con renovar el Gobierno para solucionar los problemas, no basta; tampoco diré que sea tarea fácil, no será tarea fácil; al contrario, lograr que los españoles pongan el pie en la senda de la recuperación me parece una obra titánica. Lo que sí quiero decir es que España quiere hacerlo, que se puede hacer, y que como se puede hacer tenemos el deber moral de hacerlo, y yo garantizo que lo haremos tan pronto como los españoles lo decidan y el señor Rodríguez Zapatero lo permita [Rajoy, 2011].

Aquí, entre otros mecanismos, destacan tres figuras oratorias que cumplen diferentes funciones en el mensaje (LC, "El español que hablamos", La voz de Almería, 26/11/2012, p. 27).

El estilo directo, tanto por medio de comillas, cursivas, con verbo introductor o sin él, se convierte también en una señal de distanciamiento por parte del locutor. En (6), en una columna de Ramón Carnicer, este se aleja de lo que dice la persona "casi analfabeta" que conoce, para presentar esas palabras con efectos humorísticos:

6) Conozco una persona casi analfabeta que a los autobuses de dos pisos, abundantes hasta hace poco en Barcelona, les llamaba "altobuses", y al sommier, "suñé" (forma esta muy generalizada); "paratrapo", al esparadrapo, y "positorios" o "depositorios" a los supositorios (RC, "Etimología popular", Sobre el lenguaje de hoy, 1969, p. 43).

El locutor deja que el lector "escuche" directamente lo que dice el "enunciador primitivo", con el objeto de señalar que no se responsabiliza de ese discurso e indicar que las palabras entrecomilladas presentan "dimensiones ridiculizables" (Gutiérrez Ordóñez, 2003, pp. 54-55). Precisamente, otro columnista, Luis Magrinyà, explica esta función distanciadora de las comillas en el discurso polifónico:

Como ocurre con los usos muy difundidos, el gesto de las comillas se aplica ya indiscriminada y automáticamente, y resulta curioso verlo a veces hacer de forma viciosa, sin que signifique nada. Pero, cuando significa, suele dar a entender que lo que uno está diciendo no hay que tomarlo muy en serio. [...] Lo entrecomillado es siempre discurso transmitido, discurso de otros, y gracias al gesto podemos marcar 
una frontera entre lo que nosotros decimos y lo que hemos oído decir. Tiene un sentido cautelar, preventivo: "ojo, esto no lo estoy diciendo yo", avisamos (LM, "Entre comillas", "Lengua y Literatura", El País digital, Madrid, 28 febrero 2009, en línea).

Sin embargo, en otra columna, el mismo Magrinyà emplea las comillas con una función distinta. En (7), "poét." alude a la marca de ámbito o nivel de uso asociada a determinadas palabras en el diccionario. Habla en concreto de un ámbito "socorrido", puesto que en él se incluye un gran número de palabras y expresiones empleadas en sentido metafórico, que el columnista critica por su abuso y empleo inadecuado en cierta literatura:

7) Estrellas en el cielo, luciérnagas en los bosques, nubes en el manto (celeste), la luna en el mar: recordemos que estamos en el ámbito más socorrido de lo "poét.", donde es frecuente perlar allí donde se habría podido salpicar, otra metáfora recurrente, pero sin duda menos enjoyada, para expresar la acción de esparcir o diseminar alguna cosa (LM, “Joyería y fisiología”, El País digital, 31/01/2014).

Otro uso de las comillas o, en alternativa, de los guiones, se produce cuando el autor de la columna adopta la estrategia de la oralidad fingida, a través de la reproducción de un diálogo que puede ser real o fingido, pero que resulta verosímil en ese contexto. Se trata de un recurso creativo que se ha encontrado solo en algunos columnistas (El Brocense, Lázaro Carreter, Marqués de Tamarón), que lo emplean a menudo también con intención humorística:

8) Si un autor consagrado llama a su obra algo tan inane como "Queremos tanto a Glenda", lo peor que le puede ocurrir es que el lector la pida diciendo "deme eso de Amamos a Greta..., no, creo que se llama Tessa nos gustaba a todos..., bueno, ya sabe usted, el útimo de Cortázar”. [...] Así fue como uno de nuestros investigadores oyó preguntar en una tienda por las "Cartas de un viejo verde". Se refería, claro estaba, a las "Cartas de amor de un sexagenario voluptuoso", de Delibes (MdT, "De tomos y lomos”, $A B C, 25 / 05 / 1985$, p. 67).

9) Se decía que en los primeros años de este siglo hubo en Barcelona un ricacho que se dedicaba a editar libros y álbumes exclusivamente dedicados a la belleza de las mujeres, más o menos “in puris naturabilis". Un día llamó al hombre que dirigía sus publicaciones y le dijo: "Tiene usted que hinchar la publicidad de este nuevo libro. Fíjese bien: ¡Qué redondeces, qué pantorrillas, qué pecho!”. Y, finalmente, y un poco extasiado, exclamó: "No tiene usted más remedio que buscar nuevos adjetivos. Los de ahora están muy gastados. Mire, mire usted esto. Es algo que no se ha publicado nunca. Hay que hacer una campaña colosal, una campaña sicalíptica.”

—¿Qué ha dicho usted?, preguntó el director.

- He dicho sicalíptica, eso de la Biblia.

— ¿De la Biblia?

- Sí, señor, de la Biblia, estoy seguro.

-Pues adelante. Haremos propaganda sicalíptica.

El "mandamás" había querido decir "apocalíptica", o sea, una extrema ponderación del desnudo femenino. La palabra hizo carrera, y sicalípticas se llamaron desde entonces todas las revistas, todos los libros —y había cantidad — que utilizaban las turgencias femeninas como apetito de voluptuosidades (El Brocense, "Sicalipsis", $A B C, 14 / 07 / 1984$, p. 54).

En (8), pensando en determinados escritores que se nombran de forma explícita y en los títulos de algunas de sus novelas, el Marqués de Tamarón da voz a uno de esos autores: "llama a su obra algo tan inane como 'Queremos tanto a Glenda'”, para escenificar un hipotético diálogo entre el lector y el librero, en el que 
destaca de forma irónica el carácter insustancial y poco memorable de ese título. La reproducción de las palabras de esos dos enunciadores se hace de forma lo más verosímil posible mediante, por ejemplo, la adopción en la escritura de elementos prototípicos del registro oral coloquial en boca del lector que busca ese libro. Con el mismo objetivo pero de forma distinta, reproduce una segunda situación de enunciación, en este caso, posiblemente real, a propósito del título de una novela de Miguel Delibes. Aquí el columnista retoma las circunstancias donde se produjo el intercambio, así como las palabras de uno de "sus investigadores" (suponemos que se trata de un lector asiduo de la columna que envía al autor usos censurables de la lengua), mediante las cuales se subraya la dificultad de recordar ciertos títulos.

En (9) se asiste a una conversación que El Brocense elabora introduciendo mediante citas y guiones distintas voces, que hablan de forma directa, desde su universo referencial. Al lector se le presenta una escena en la que un editor barcelonés de publicaciones éroticas da indicaciones a su impresor para lanzar una campaña "sicalíptica". El universo recreado por medio de ese diálogo permite al columnista explicar de forma creíble y con humor, cuál es el origen de ese adjetivo que el Diccionario de la lengua española recoge hoy en día como "creación arbitraria" (DLE, 2014) perteneciente a "sicalipsis" (derivado regresivo del adjetivo, con el significado de "Malicia sexual, picardía erótica"). El diálogo tiene aquí el efecto de resaltar el dinamismo de los hechos narrados. Por otra parte, contribuye a limitar la presencia del columnista que se esconde detrás de los diálogos, y que entra de nuevo en escena como locutor-narrador únicamente para aclarar que el potente editor confunde "apocalíptica" con el adjetivo que acabará imponiéndose, a pesar de la perplejidad de su impresor. Como vemos, en estos fragmentos se entrecruzan las voces del locutor y las de distintos enunciadores, sin que haya marcas en el texto ni señales sintácticas de subordinación. Se trata de un discurso vivido en función de reflejo en el que el locutor borra su presencia, aparentemente sin que nadie dirija la narración, en cierto modo para distanciarse. Sin anunciarlo previamente, el locutor abandona su voz y su visión de las cosas colándose en las de los personajes, de modo que confunde los planos de focalización.

Como se apuntaba, son numerosos los casos en los que se pasa del estilo directo al indirecto, mezclando ambos procedimientos en la columna. En los textos analizados se recurre a la cita indirecta prototípica empleando generalmente verbos de comunicación y subordinadas sustantivas encabezadas por que, como en los siguientes fragmentos:

10) También se cuenta que el mismo Sir Winston [Churchill], en otra rabieta durante la segunda guerra mundial, al recibir una nota informativa con gazapos que indución a error entre Irán e Irak, exigió que en adelante los papeles que llegaran a sus manos se refiriesen a dichos países como Persia y Mesopotamia [...] (MdT, "Maputo y otros topónimos", $A B C, 17 / 08 / 1985$, p. 45).

11) Uno de los especialistas con mejor conocimiento de todo lo concerniente a la fórmula 1 explicaba el domingo 27 de abril en la radio que Kimi Raikkonen había tenido problemas en el trasero. A usted le habrá parecido al leer esa frase (como a mí al escucharla) que el piloto finlandés estuvo incómodo en su monoplaza tal vez por alguna deficiencia en el asiento (ÁG, "Problemas en el trasero", El País digital, $11 / 05 / 2014)$.

A través de esta modalidad, se recontextualiza el enunciado original gracias al marco que incluye el verbo de comunicación o pensamiento (contar, exigir, 
explicar, parecer), la mención al locutor del discurso original y los indicios externos o circunstancias que rodean la situación enunciativa originaria (Méndez García de Paredes, 1999, p. 108). Estos elementos permiten al autor recrear la escena, así como la actitud enunciativa de los diferentes enunciadores citados. Véase el caso de Wiston Churchill que exige "en otra rabieta" que le hablen de Persia y Mesopotamia y no de Irán o Irak (10) o del lector de Grijelmo (11), que "al leer esa frase" habrá interpretado lo dicho por el especialista en fórmula 1 en un determinado sentido. Es necesario recordar la distinción entre la lectura de re, propia del estilo indirecto, en la que el contenido de las expresiones referenciales trasladadas pertenecen al mundo del locutor, y la lectura de dicto, correspondiente al estilo directo, en la que "la responsabilidad de la expresión (y con ella del punto de vista, valoración, etc.) se atribuye al hablante citado" (Reyes, 1993, p. 20). En relación con este aspecto, cabe señalar que los verbos que se emplean como marco de cita en las columnas analizadas indican a menudo la actitud subjetiva del locutor que puede ser de aprobación o de rechazo de determinados usos lingüísticos o de las prácticas lingüísticas de ciertos hablantes. En el primer caso, suelen introducir un argumento de autoridad, una voz que se origina a menudo en los propios conocimientos del autor sobre la lengua, conocimientos "que él mismo autoriza mediante la confrontación con lo dicho por la Academia sobre el aspecto que valora" (Martínez Egido, 2019, 2020). De ahí que sea habitual en estos textos citar distintas obras lexicográficas para declarar si un préstamo puede considerarse válido:

12) Pasando ahora al ramo de la alimentación, hay que señalar como novedad el champiñón. Esta palabra figura condenada en el Diccionario Manual con un asterisco infamante y calificada, con toda razón, de galicismo (JC, "La Academia española trabaja", $A B C, 28 / 03 / 1963$, p. 3).

En este caso, Julio Casares declara explícitamente su adhesión a la decisión recogida en el Diccionario manual e ilustrado de la lengua española (edición de 1950), de condenar con un asterisco el galicismo champiñón. En otros casos, se señala la autoridad de algunos lingüistas y académicos (e incluso columnistas) sobre la difusión de ciertas palabras en el español (13):

13) Dice don Emilio Lorenzo que ésas y otras muchas más palabras, aunque no sean tan chabacanas, se están difundiendo con tanto arranque que no ya en decenios, sino en poco tiempo, se generalizará su uso [...] (LC, El Brocense, "El inglés romanizado", "Diálogo de la lengua", $A B C, 07 / 07 / 1984$, p. 54).

Como vemos, las formas de cita son, con pocas diferencias, el estilo directo o indirecto y el empleo de verbos de lengua; en ocasiones, las fórmulas incluyen elementos modales. Por ejemplo, en este fragmento, Emilio Lorenzo introduce su valoración positiva de las palabras "anotadas" y "glosadas" por Emilio Náñez, a través del adverbio "brillantemente":

14) [...] las [palabras] infrecuentes, anotadas y brillantemente glosadas del español humorístico por Emilio Náñez en sus libros, tales como "descuajaringuen", "plomoscídeos", "liberticida" (EL, "Palabras con gancho (Antofagasta)", $A B C$, 20/04/1998, p. 003).

Sin embargo, en un buen número de columnas se cita el diccionario académico precisamente para desautorizarlo: 
15) No puede decirse que se haya roto la cabeza el Diccionario de la Real Academia con su definición de ropa, poco exacta y harto equívoca: "Prenda de vestir" (LM, "Lengua y Literatura", El País digital, 14/02/2014).

En estos casos en los que el discurso evocado se valora negativamente, el objetivo del autor es desactivar argumentativamente el enunciado de la cita, empleando a menudo expresiones que denotan rechazo. Véase cómo en el ejemplo se personaliza la obra académica a través de la expresión "romperse la cabeza".

Este mecanismo de desautorización funciona de forma eficaz si el columnista y sus lectores comparten planteamientos ideológicos sobre una determinada idea de qué deben o no deben incluir los diccionarios, qué tipo de definiciones son aceptables o cómo debe ser la norma lingüística que vehiculan esas obras. Por otra parte, el columnista busca aliarse con el lector en función de un imaginario similar compartido sobre los hablantes que no respetan la norma ideal o ejemplar del español que buscan elaborar a través de sus columnas (Pano Alamán, 2019). En (16), por ejemplo, se trata de "ciertos renovadores de la expresión" que "siembran sin tasa" la palabra objeto de crítica, mientras que en (17) son aquellos que "así farfullan" las dos palabras señaladas en cursiva que Lázaro Carreter censura:

16) Cuando ciertos renovadores de la expresión hablan admirativamente de Francia o de sus gentes, adoptan un aire de personas familiarizadas con la filosofía y sus misterios y siembran sin tasa el adjetivo "cartesiano" [...] (RC, "Sencillez y afectación", Sobre el lenguaje, 1969, p. 178).

17) ¡Autosuicidio y autosuicidarse! "Risum teneatis", como recomendó el clásico: reprimid la risa. Pero ¿sabrán quienes así farfullan qué significa suicidarse? (FLC, “Autosuicidio", Dardo en la palabra, 1977, p. 139).

Como vemos, los enunciados que se censuran se originan en distintas tipologías de hablante. En concreto, se apunta a un "mal hablante" que, según la clasificación de Martínez Egido (2020, p. 99), suele ser general o genérico, colectivo o gremial (político, periodista, traductor, jurista) o individual, es decir, una entidad específica (persona o institución), nombrada por el autor de la columna.

Es habitual también en estas CSL, que se desautorice lo dicho por un enunciador mencionado en el marco de la cita, a través de enunciados interrogativos orientados a que el interlocutor, el lector de la columna, confirme la suposición del columnista, que aparece contenida en el texto de forma explícita (18) o implícita (19), y que coincide con su propia opinión:

18) Ahora bien, ¿imaginan ustedes que haya habido jamás en Francia un traductor que haya vertido "ir por lana" escribiendo allez pour laine? Seguramente, no (JC, "Cosas del lenguaje”, $A B C, 30(03 / 1940$, p. 3).

19) Ya sabemos que ni la claridad ni la belleza importan mucho a los formadores de opinión. Pero ¿y la vergüenza? ¿No les dará azaro a veces pensar que pueda escucharlos su abuela del pueblo, que sin saber lo que era un adverbio modal hablaba en cristiano y se le entendía? ¿O no tendrán abuela? (MdT, "El ciempiés culilargo", $A B C, 13 / 07 / 1985$, p. 59).

Cabe notar en este último caso la negación polémica, no exenta de cierta ironía, muy presente en las columnas del Marqués de Tamarón.

Las voces citadas en estos textos son a menudo las de periodistas, políticos, autoridades de la lengua o hablantes anónimos, cuyas palabras se escuchan en diferentes contextos. En algunos casos, los columnistas dialogan a distancia con sus 
lectores potenciales adoptando una estrategia persuasiva eficaz, como hace aquí Álex Grijelmo para atraerse la buena disposición de quien lee su texto a modo de captatio benevolentiae:

20) Y esto se afirma aquí con la sana intención de que nadie deduzca de la cartelera que Invencible es la traducción más correcta de Unbroken, y con la vana esperanza de que este artículo lo consideren ustedes irrebatible o irrefutable. Incluso indiscutible (AG, “'Invencible' no es 'Unbroken'”, El País, 11/01/2015).

Otras veces el columnista cita a los lectores que se corresponden con él simplemente para indicar su fuente informativa. En este sentido, De Miguel se diferencia de otros columnistas del corpus por integrar en su discurso las palabras de sus lectores con el objeto de rechazar de forma más o menos atenuada las afirmaciones que contienen. Véase, por ejemplo, el ejemplo (4) más arriba y el siguiente:

21) Alfonso Blanco-Rivas me envía una ristra de expresiones gallegas en torno a la palabra "carallo" para que se vea lo polisémica que es. [...] Añade don Alfonso: "probablemente, si no eres gallego, no lo entiendes". Pues no soy gallego y lo entiendo perfectamente (AdM, "Lenguas hispánicas", Libertad digital, 11/11/2009).

En otra columna (22) incluye el dicho popular "confundir el culo con las témporas", que constituye en este contexto una suerte de intertexto. Se trata de un recurso habitual en también en otras CSL del corpus como en (23), donde se invita al lector a identificar el personaje de la literatura tradicional Pero Grullo que Carnicer emplea para argumentar en contra de enunciados que no aportan nada a la conversación:

22) Me dice don Rafael que no se atreve a leer ninguna novela mía "ya que la imagen que tengo de usted es la de un gran sociólogo y comunicador". Qué tendrá que ver el culo con las témporas (AdM, "Sobre el sentido de las palabras", Libertad digital, 13/04/2011).

23) [...] dijo al empleado, y a mí, que ya participaba de sus explicaciones: “¡Pero si eso es una perrogrullada!” Es decir, algo que hasta los perros saben. ¡Magnífica actualización de aquel remoto Pero Grullo, cuyas candorosas sentencias, llamadas perogrulladas, han pasado al dominio de la retórica y la erudición [...] (RC, "Etimología popular", Sobre el lenguaje, 1969, p. 44).

En este último caso es evidente el recurso a la ironía, que juega en las CSL un papel fundamental como estrategia persuasiva (Pano Alamán, 2019). Permite al locutor desdoblarse en distintos puntos de vista que se oponen entre sí, invitando al lector a inferir qué posición toma realmente el autor de la columna:

24) Como queda recogido en el Diario de sesiones, el líder socialista evitó el término crisis y lo sustituyó por los siguientes sintagmas: "situación ciertamente difícil y complicada", "condiciones adversas" "una coyuntura económica claramente adversa" [...]. ¡Espléndido estuvo, lingüísticamente hablando, el Presidente! ¡Qué manera de agrandar y engrandecer la lengua española! (LC, "El lenguaje político, la derecha y la izquierda", La Voz de Almería, 09/11/2009, p. 41).

Como se ha visto en estos fragmentos, los puntos de vista evidenciales que aparecen en las CSL son directos. El cotexto contiene la mención de un acto de habla que cumple la función de fuente explícita, esto es, que funciona como punto de vista evidencial y que contiene las instrucciones dialógico-causales que permiten 
recuperar los marcos de discurso previos sobre los que el columnista elabora su argumentación (García Negroni, 2016). Por ello, en la mayor parte de los ejemplos, vemos que el posicionamiento subjetivo del hablante se manifiesta a través de enunciaciones asertivas; en otros casos, si bien el punto de vista evidencial es directo, el columnista vehicula su opinión de forma más atenuada. Este es el caso del siguiente fragmento, en el que el discurso ajeno en el que se reproducen la palabras "oídas" en la televisión está introducido por un verbo de lengua (llamar) y que sin otras marcas explícitas alude a un ellos no identificado:

25) Basta, sin embargo, con enchufar la televisión media hora al año -como hacemos nosotros en abnegado sacrificio por nuestros lectores- para oír varios disparates comparables. A veces traducen guiados por falsos amigos y llaman, por ejemplo, hierbas salvajes al benéfico poleo o a la humilde yerbaluisa, como si de feroces plantas carnívoras se tratase [...] (MdT Deliberando groserías, $A B C, 12 / 10 / 1985$, p. $61)$.

\section{Conclusiones}

Este estudio cualitativo ha intentado mostrar que la polifonía es un recurso pragmático-discursivo definidor de las CSL, publicadas durante décadas en la prensa española. Se trata de una estrategia argumentativa y persuasiva presente en todas las columnas analizadas que se manifiesta a través de distintos procedimientos gramaticales y discursivos. La mayor parte de los columnistas emplea el estilo directo prototípico de reproducción del discurso ajeno, citando entre comillas o poniendo en cursivas, oraciones, expresiones o palabras que consideran inadecuadas en un determinando contexto de uso o que son inaceptables en función de su ideología lingüística. Otros recursos polifónicos empleados en estos textos como estrategia argumentativa, pero también con clara intención persuasiva para ganarse al lector, son la oralidad fingida o el perspectivismo dialógico con efecto humorístico -en particular, en El Brocense, el Marqués de Tamarón y Lázaro Carreter-, los enunciados interrogativos (preguntas retóricas) y la ironía. En la Tabla 2 se recogen los principales procedimientos polifónicos empleados en el corpus:

Tabla 2. Procedimientos polifónicos en las CSL

\begin{tabular}{|l|}
\hline Estilo directo \\
\hline Estilo indirecto \\
\hline Estilo directo libre \\
\hline Estilo indirecto libre \\
\hline Perspectivismo dialógico (oralidad fingida) \\
\hline Enunciado interrogativo \\
\hline Negación polémica \\
\hline Ironía \\
\hline Intextexto \\
\hline
\end{tabular}

El marco de la cita, a través del verbo introductor o incluso mediante adjetivos o adverbios con función modalizadora, indica la actitud subjetiva del columnista, su conformidad o rechazo respecto al enunciado que aparece reproducido. En ocasiones, manifiestan su adhesión a algunas definiciones de las obras académicas o a lo publicado o dicho por lingüistas, filólogos o escritores, que se citan como argumentos de autoridad. Sin embargo, la mayoría expresa su rechazo o asombro ante enunciados proferidos por ciertos escritores, periodistas, políticos y hablantes en general, que desconocen o ignoran los significados de las palabras o 
que las emplean con afectación o sin reflexionar. En estos casos es frecuente que el columnista se alíe con el lector contra esos enunciadores por medio de enunciados interrogativos o de la inclusión en el propio discurso de las palabras o pensamientos del lector, bien para dialogar en la distancia, bien para hacerle reflexionar críticamente sobre la lengua, invitándole a adherirse a su opinión.

\section{Referencias}

\section{Referencias primarias}

1. Calvo, Luis "El Brocense" (1980-1984), "Diálogo de la lengua", ABC.

2. Carnicer, Ramón (1969), Sobre el lenguaje de hoy, Madrid, Editorial Prensa Española.

3. Casares, Julio (1959-1965), "La Academia Española trabaja", ABC.

4. Cortés Rodríguez, Luis (2009-2011), "El español que hablamos", La Voz de Almería.

5. Grijelmo, Álex (2013-2019), "La punta de la lengua", El País.

6. Lázaro Carreter, Fernando (1997), El dardo en la palabra, Madrid, Galaxia Gutenberg.

7. Lázaro Carreter, Fernando (2003), El nuevo dardo en la palabra, Madrid, Alianza.

8. Lorenzo, Emilio (1982-2002), $A B C$.

9. Magrinyà, Luis (2009-2014), "Lengua y Literatura", El País.

10. Miguel, Amando de (2002-2005): "Errores y Erratas", Libertad digital.

11. Mora Figueroa, Santiago de (1985-1988), "El habla nacional", $A B C$.

\section{Referencias secundarias}

1. Bajtin, M. (1981). The Dialogic Imagination. Austin: University of Texas Press.

2. Bruzos Moro, A. (2009). La polifonía. En Ruiz Gurillo, L. y Padilla García, X. A. (Eds.), Dime cómo ironizas y te diré quién eres. Una aproximación pragmática a la ironía (pp. 45-64). Frankfurt, Peter Lang.

3. Carriscondo Esquivel, F. y Guerrero Salazar, S. (2015) (Eds.). Proyecto Lengua y Prensa. Málaga, Fundación Alonso Quijano.

4. Casado Velarde, M. (2010). Algunas estrategias para la desautorización del discurso ajeno en la prensa. En Martínez Pasamar, C. (Ed.), Estrategias argumentativas en el discurso periodístico (pp. 87-118). Bern, Peter Lang.

DOI: https://doi.org/10.4067/S0718-09342013000300003

5. Casado Velarde, M. y De Lucas, A. (2013). La evaluación del discurso referido en la prensa a través de los verbos introductores. Revista Signos, 46(83), pp. 332-360.

6. De Lucas Vicente, A. (2017). Polifonía y argumentación: Estrategias de introducción de discurso ajeno en un corpus de prensa española actual. Tesis de Doctorado. Universidad de Navarra. Recuperado de:

http://adelucas.es/wp-content/uploads/2019/07/Tesis-v.4.pdf

7. Donaire, M. ${ }^{a}$ L. (1997). Polifonía en condicional, Théleme, 11, pp. 303-313.

8. Ducrot, O. (1986 [1984]). El decir y lo dicho. Polifonía de la enunciación. Barcelona, Paidós.

9. Escribano Hernández, A. (2009). Las voces del texto como recurso persuasivo. Madrid, Arco Libros.

10. Escribano Hernández, A. (2017). La polifonía como mecanismo argumentativo en la retórica editorial. Círculo de Lingüística Aplicada a la Comunicación, 72, p. 111-132. Recuperado de: http://www.ucm.es/info/circulo/72/escribano.pdf

DOI: https://doi.org/10.5209/CLAC.57905

11. Estévez Rionegro, N. (2012). Discurso referido y procedimientos de cita en la prensa escrita actual. En Álvarez, P., Amorós, C., Fernández del Viso, M., Gago, L., García, V., López, J., Martín, L., Sánchez, C. y Sánchez, R. (Eds.), Interlingüística XXII (pp. 337347). Salamanca, Asociación Jóvenes Lingüistas y Luso-Española de Ediciones.

12. Fuentes Rodríguez, C. (1998). Estructuras parentéticas. Lingüistica Española Actual, 20(2), pp. 137-174.

13. García Negroni, M. M. (2016). Polifonía, evidencialidad y descalificación del discurso ajeno. Letras de Hoje, 51(1), pp. 7-16. DOI: https://doi.org/10.15448/1984- 


\subsection{6 .1 .23851}

14. García Negroni, M. M. y Tordesillas Colado, M. (2001). La enunciación en la lengua. De la deixis a la polifonía. Madrid, Gredos.

15. González Ruiz, R. y Loureda Lamas, Ó. (2005). Algunos estudios recientes sobre lo metalingüístico en español. Verba, 32, pp. 351-369.

16. Gutiérrez Ordóñez, S. (2003). Comentario pragmático de textos polifónicos. Madrid, Arco Libros.

17. Houdebine, A. M. (2002). L'Imaginaire linguistique et son analyse, Travaux de linguistique, 7, pp. 11-27.

18. Maldonado González, C. (1999). Discurso directo y discurso indirecto. En Bosque, I. y Demonte, V. (Eds.), Gramática descriptiva de la lengua española (pp. 3549-3596). Madrid, Espasa-Calpe, vol. 3.

19. Marimón Llorca, C. (2020) (Ed.). El columnismo lingüístico en España desde 1940. Análisis multidimensional y caracterización genérica. Madrid, Arco Libros.

20. Marimón Llorca, C. (2018). "La Academia española trabaja": Actitudes lingüísticas y estrategias valorativas en las columnas sobre la lengua, Cuadernos AISPI, 12, pp. 169190.

21. Marimón Llorca, C. (2015). Ideologías lingüísticas del español: la dimensión política del panhispanismo en los Congresos Internacionales de la Lengua Española. Circula. Revue d'Idéologies Linguistiques, 1, pp. 110-129.

22. Marimón Llorca, C. (2016). Rhetorical strategies in discourses about language: the persuasive resources of ethos. Res Rhetorica, 1(16), pp. 67-89.

23. Marimón Llorca, C. y Santamaría Pérez, I. (Eds.). (2019), Ideologías sobre la lengua y medios de comunicación escritos. El caso del español. Berlin, Peter Lang. DOI: https://doi.org/10.3726/b15242

24. Martínez Egido, J. J. (2019). Lo académico como argumento de autoridad: perspectiva ideológica de los columnistas ante la norma académica. En Marimón Llorca, C. y Santamaría Pérez, I. (Eds.), Ideologías sobre la lengua y medios de comunicación escritos. El caso del español (pp. 175-192). Berlin, Peter Lang.

25. Martínez Egido, J. J. (2020). Las CSL como discurso argumentativo: el caso del mal hablante. En Marimón Llorca, C. (Ed.). El columnismo lingüístico en España desde 1940. Análisis multidimensional y caracterización genérica (pp. 79-104). Madrid, Arco Libros.

26. Martínez Linares, M. A. (2019). Lo que sugieren las columnas de Álex Grijelmo sobre el potencial ideológico del verbo y su proyección en un corpus de noticias. En Marimón Llorca, C. y Santamaría Pérez, I. (Eds.), Ideologías sobre la lengua y medios de comunicación escritos. El caso del español (pp. 293-312). Berlin, Peter Lang.

27. Méndez García de Paredes, E. (1999). Análisis de la reproducción del discurso ajeno en los textos periodísticos. Pragmalingüística, 7, pp. 99-128.

DOI: https://doi.org/10.25267/Pragmalinguistica.1999.i7.04

28. Méndez García de Paredes, E. (2000). La literalidad de la cita en los textos periodísticos. Revista española de Lingüística, 30(1), pp. 147-167.

29. Méndez García de Paredes, E. (2001). Análisis de las formas de introducir el discurso ajeno en los textos periodísticos: El contexto reproductor, en Bustos Tovar, J. J., Charaudeau, P., Girón Alconchel, J. L., Iglesias Recuero, I. y C. López Alonso (Eds.), Lengua, discurso y texto (pp. 2082-2098). Madrid, Visor.

30. Pano Alamán, A. (2020). Las CSL como discurso lúdico. La ironía y el humor al servicio de la persuasión. En Marimón Llorca, C. (Ed.). El columnismo lingüístico en España desde 1940. Análisis multidimensional y caracterización genérica (pp. 31-52). Madrid, Arco Libros.

31. Pano Alamán, A. (2019). La ironía y el humor al servicio de la norma ejemplar en los 'dardos' de Fernando Lázaro Carreter, en Marimón Llorca, C. y Santamaría Pérez, I. (Eds.), Ideologías sobre la lengua y medios de comunicación escritos. El caso del español (pp. 339-355). Berlin, Peter Lang.

32. Perelman, Ch. y Olbrechts-Tyteca, L. (1989 [1958]). Tratado de la argumentación. La nueva retórica. Madrid, Gredos.

33. Real Academia Española (2009). Nueva Gramática de la Lengua española. Madrid: Espasa.

34. Remysen, W. (2005). La chronique de langage à la lumière de l'expérience canadienne-française: un essai de définition, en Bérubé, J., Gauvin, K. y Remysen, W. 
(Eds.), Journées de linguistique (pp. 267-281). Québec, Centre de Recherches sur les Activités Langagières.

35. Reyes, G. (1993). Los procedimientos de cita: estilo directo y estilo indirecto. Madrid, Arco Libros.

36. Reyes, G. (1994). Los procedimientos de cita: citas encubiertas y ecos. Madrid, Gredos.

37. Schieffelin, B., Woolard, K. A. y Kroskrity, P. V. (Eds.). (2012 [1998]). Ideologías lingüísticas. Práctica y teoría. Madrid, Libros de la Catarata.

38. Valle, J. del (Ed.). (2007). La lengua, ¿patria común?: ideas e ideologías del español. Frankfurt-Madrid, Iberomericana-Vervuert.

39. Van Dijk, T. (2011). Sociedad y discurso. Barcelona, Gedisa.

40. Villa García, M. Á. y Arroyas Langa, E. (2019). El discurso referido en los artículos de opinión. Análisis del diálogo en las columnas de Alfonso Sánchez. Vivat Academia. Revista de Comunicación, 148, pp. 101-119.

DOI: $\underline{\text { https://doi.org/10.15178/va.2019.148.101-119 }}$ 